\title{
Exposure to teachers smoking and adolescent smoking behaviour: analysis of cross sectional data from Denmark
}

\author{
L H Poulsen, M Osler, C Roberts, P Due, M T Damsgaard, B E Holstein
}

Tobacco Control 2002;11:246-251

See end of article for authors' affiliations

Correspondence to Lis Hentze Poulsen,

University of Copenhagen,

Institute of Public Health,

Department of Social

Medicine, Blegdamsvej 3,

DK-2200 Copenhagen,

Denmark;

l.hentze@socmed.ku.dk

Received 6 July 2001 and revision requested

9 November 2001

Accepted 13 March 2002

\begin{abstract}
Objective: To determine whether adolescent smoking behaviour is associated with their perceived exposure to teachers or other pupils smoking at school, after adjustment for exposure to smoking at home, in school, and best friends smoking.

Design: Logistic regression analysis of cross sectional data from students in Denmark.

Subjects: 1515 grade 9 students (mean age 15.8) from 90 classes in 48 Danish schools.

Outcome measure: Self reported smoking behaviour; daily smoking and heavy smoking, defined as those smoking more than 20 cigarettes per week.

Results: Of the students in this study, $62 \%$ of boys and $60 \%$ of girls reported being exposed to teachers smoking outdoors on the school premises. The proportion of boys and girls reporting to have been exposed to teachers smoking inside the school building were $86 \%$ and $88 \%$, respectively. Furthermore, $91 \%$ of boys and $92 \%$ of girls reported that they had seen other students smoking outdoors on the school premises. Adolescents' perceived exposure to teachers smoking outdoors on the school premises was significantly associated with daily smoking, having adjusted for sex, exposure to teachers smoking indoors at school and pupils smoking outdoors at school, as well as the smoking behaviour of mother, father, and best friend (odds ratio (OR) 1.8, 95\% confidence interval 1.2 to 2.8). Adolescents' perceived exposure to teachers smoking inside the school building was not associated with daily smoking (OR $0.9,95 \% \mathrm{Cl} 0.5$ to 1.6 ) and perceived exposure to pupils smoking outdoors was not associated with daily smoking (adjusted $\mathrm{OR} 1.5,95 \% \mathrm{Cl} 0.5$ to 4.4 ). There were similar findings with heavy smoking as the outcome variable.

Conclusions: Teachers smoking during school hours is associated with adolescent smoking. This finding has implications for future tobacco prevention strategies in schools in many countries with liberal smoking policies where it might provide support for those working to establish smokefree schools.
\end{abstract}

T he health effects of smoking are well documented and it is estimated that half of those who smoke and fail to stop will die from their habit. ${ }^{1}$ Given that most smokers take up the habit before they reach the age of 18 years, one of the most important strategies in reducing smoking prevalence in the population has been to prevent young people from becoming smokers. ${ }^{2}$ After a period of stability in adolescent smoking prevalence in western Europe, it would appear that the rate of smoking among young people has risen in recent years in many countries. ${ }^{34}$ In 1994, the proportion of smokers among Danish adolescents aged 15 was 33\% for girls and 25\% for boys; by 1998, these proportions had changed to $38 \%$ for boys and $31 \%$ for girls. ${ }^{45}$ These trends indicate the need for new smoking prevention strategies based on a more rigorous understanding of the factors which influence adolescents' initiation of smoking.

In their review of predictors of onset of adolescent smoking, Conrad et al identified a variety of factors that might influence young people to smoke: sociodemographic factors (for example, socioeconomic status, sex, age, availability of spending money), social bonding factors (including family bonding, peer bonding, and school influences), social learning factors (including family smoking and peer smoking), and personal factors (including low self-esteem, refusal skills, beliefs and attitudes toward smoking). ${ }^{6}$ Furthermore, social psychological theories and research have enabled us to understand better the processes underlying adolescent smoking behaviour. ${ }^{7}$

According to the theory of planned behaviour, intentions are the immediate determinant of behaviour. ${ }^{8}$ It could be argued that students in a school where smoking restrictions were absent would perceive smoking as being acceptable, resulting in intentions to take up the habit. Social cognitive theory, on the other hand, states that adolescents' smoking behaviour is acquired through observing the behaviour of role models in the social environment. ${ }^{9}$ The theory suggests that approval of smoking by friends, parents, and other key persons is likely to increase the probability of smoking, through the imitation of powerful role models. Long term empirical studies examining social environmental factors that might influence adolescent smoking behaviour support the notion that modelling is a predictor of smoking, with the impact of smoking by family members and peers being addressed in a large number of studies. Parental and sibling smoking behaviour, parental attitudes toward smoking, and sibling pressure have all been found to be predictive of smoking onset, with less support for parental smoking and approval. In particular, the influence of peers is considered to be one of the most important predictors of adolescent smoking, more so than parental smoking. ${ }^{6}{ }^{10}$ However, recent research suggests that the influence of peers may have been overstated, with selection and projection increasing the association between friends' and adolescents' behaviour. ${ }^{11}$ Adolescents, it is argued, who already smoke are more likely to seek out and spend time with other smokers, and adolescents who smoke tend to overestimate the smoking prevalence of their friends.

The school setting represents another crucial arena in which learning may take place. The school has long been considered an important setting for child development and health behaviours, and many smoking prevention programmes are school based. ${ }^{12}$ Measures of school related predictors of adolescent smoking have included, for example, alienation from school and low academic achievement. ${ }^{6}{ }^{13}$ Furthermore, the student's perception of the school environment-for example, low teacher support and inadequate demands- 
appear to be related to smoking initiation. ${ }^{14}$ However, little is known about how school smoking practices are related to adolescent smoking behaviour. The small number of studies that have looked at the effects of school smoking policy on adolescent smoking behaviour suggest that the prevalence of smoking declines when there is a ban on student smoking on the school grounds $\mathrm{s}^{12}{ }^{15}$ and that there is a positive association between the provision of student smoking areas and the proportions smoking. ${ }^{16}$ Recent work in the USA indicated that school smoking restrictions were associated with reduced smoking prevalence, but only when the restrictions were strongly enforced. ${ }^{17}$ Although there are barriers to developing, implementing, and monitoring smoking policies in schools, ${ }^{18}$ they are likely to require minimal funding and staff commitment. ${ }^{12}$ This area has attracted relatively little attention in smoking research. Thus, in future intervention strategies aimed at preventing use of tobacco by adolescents, it is important to gain more knowledge about how school smoking practices relate to adolescent smoking behaviour. This paper presents an analysis of cross sectional data collected in Denmark in 1998. The main purpose of the analysis is to examine the extent to which adolescent smoking behaviour is associated with perceived exposure to teachers and other pupils smoking at school. Denmark was an ideal setting for this kind of analysis because the smoking policies at school in 1998 were lenient. Denmark had legislation restricting smoking in public buildings, but this legislation did not apply to schools, as Danish schools were under the jurisdiction of individual school boards. For this reason, smoking restriction policies varied from schools with no restrictions at all to schools where smoking was prohibited at all places except for the staff room. In 1998, 70\% of the schools allowed teachers' smoking outdoors and $70 \%$ of the schools permitted smoking among older pupils. ${ }^{19-22}$

\section{METHODS \\ Subjects}

A cluster sampling procedure was used. Overall 64 schools were randomly selected across Denmark, following stratification by size (number of students) and location, to ensure representation from larger city areas. Of these, 55 schools agreed to participate, of which 48 contained ninth grade classes. All 95 ninth grade classes in these schools were selected. Overall, 1578 ninth grade students aged 15-16 years (mean age 15.8 years) completed a questionnaire, which corresponded to $99 \%$ of the pupils present on the day of the survey and $91 \%$ of all pupils of this age. Five classes with less than 10 students $(\mathrm{n}=32)$ and students without any class identification $(\mathrm{n}=31)$ were excluded. Thus, the present study is based on 1515 students.

\section{Measurements}

Following pilot work, data were collected during 1998 (school year 1997-98) by means of a standardised self completion questionnaire. Students completed the questionnaire in the classroom during school hours, and were instructed not to provide their name or date of birth. Data collection was administered by teaching staff, following prior approval for the study by the school board.

Smoking behaviour was assessed by asking the students "How often do you smoke at present" (daily, weekly, less often, don't smoke). In the present study the responses were dichotomised as $0=$ daily smokers and $1=$ weekly/less often/nonsmokers. The students were also asked "How many cigarettes do you usually smoke per week". The responses were dichotomised as $0=$ more than 20 cigarettes per week (heavy smokers) and $\mathrm{l}=20$ or fewer cigarettes per week/nonsmokers. Item non-response accounted for fewer than $2 \%$ $(n=17)$ of cases for both outcome variables.
The students' perception of teachers smoking was measured using four items, asking the students "During school hours, how often do you see or know about teachers smoking: in the staff room, in corridors, in other parts of the school building and outdoors on the school premises" (daily, sometimes, never, don't know). The perception of smoking by teachers was categorised into teachers smoking outdoors on the school premises and teachers smoking inside the school building. For these two variables, responses were dichotomised, such that $0=$ every day or sometimes and $1=$ never or don't know. Finally students' perceptions of other students' smoking was assessed by asking them "During school hours, how often do you see or know about other pupils smoking outdoors on school premises/playground". This variable was also dichotomised with $0=$ every day or sometimes and $\mathrm{l}=$ never or don't know.

In order to adjust analyses for other key variables known to be associated with smoking, measures of exposure to smoking among parents, friends, and school friends were also included. While the range of factors associated with adolescent smoking is vast, we chose to focus on those most strongly associated with smoking behaviour. In our analyses, these were parental smoking, peer smoking, the proportion of smokers in the class, and sex. Parental and peer smoking behaviour was assessed by three items: "Do any of the following people smoke: (a) Father; (b) Mother; and (c) Best friend" (daily, sometimes, don't smoke, don't know, don't have or don't see that person). These variables were also dichotomised (coded: $0=$ smokes daily/sometimes; $1=$ non-smoker/don't know, don't have, don't see that person). A variable measuring the proportion of smokers in the class was also included. This variable was constructed such that $0=$ classes where more than $20 \%$ of students in the class reported smoking, and $\mathrm{l}=$ classes where fewer than $20 \%$ of students reported smoking.

Participants with missing values for one or more of the variables included in the statistical models were excluded from the analysis. The number of participants excluded was 213 in the analyses for daily smoking and 198 for heavy smoking. Examination of these excluded cases showed that they had a similar distribution by sex and smoking status as those included in the analyses presented here. Thus all analyses were conducted on the subgroups of 1302 or 1317 students with complete information for all variables.

\section{Data analysis}

The students were sampled in clusters, with the school as the primary sampling unit. Consequently, students cannot be assumed to be independent, as those within the same school tend to be more alike than students generally (intraclass correlation). The presence of clustering would be expected to result in higher standard errors compared with a similar size of sample obtained using simple random sampling. To overcome this problem, an estimate for the design effect was calculated using Danish data from an earlier study and used to construct adjusted estimates of standard errors and confidence intervals. The design effect for smoking was estimated to be 1.44 , resulting in $95 \%$ confidence intervals (CI) of approximately $\pm 3 \%{ }^{3}$ As such, the data are presented in this paper with $98 \%$ CI.

Associations between smoking behaviour and perceived exposure to student and teacher smoking were assessed using bivariate and multivariate analyses, adjusting for parental smoking, best friends smoking, proportion of smokers in the class, and sex. Risk ratios-a measure of the association between exposure to others smoking and adolescent smoking behaviour-were estimated by odds ratios (ORs). ${ }^{23}$ In order to account for potential confounding, a multivariate logistic regression model was constructed including the individual risk factors outlined above and adjusted ORs were estimated. 
Table 1 Smoking behaviour among students, and their exposure to parents, teachers, friends, and classmates smoking

\begin{tabular}{|c|c|c|}
\hline & Boys $(\%(n))$ & Girls (\% (n)) \\
\hline $\begin{array}{l}\text { Adolescents smoking prevalence } \\
\text { Daily smokers } \\
\text { Weekly smokers } \\
\text { Less than weekly } \\
\text { Do not smoke } \\
\text { Frequency missing }=17\end{array}$ & $\begin{array}{l}16 \%(114) \\
5 \%(38) \\
10 \%(75) \\
69 \%(507)\end{array}$ & $\begin{array}{l}22 \%(169) \\
7 \%(55) \\
10 \%(77) \\
61 \%(463)\end{array}$ \\
\hline $\begin{array}{l}\text { Number of cigarettes smoked per wee } \\
>20 \\
1-20 \\
0\end{array}$ & $\begin{array}{l}13 \%(95) \\
11 \%(84) \\
76 \%(564)\end{array}$ & $\begin{array}{l}19 \%(145) \\
15 \%(115) \\
66 \%(512)\end{array}$ \\
\hline $\begin{array}{l}\text { Exposed to teachers smoking outdoors } \\
\text { Every day } \\
\text { Sometimes } \\
\text { Never } \\
\text { Frequency missing=31 }\end{array}$ & $\begin{array}{l}15 \%(107) \\
47 \%(338) \\
38 \%(276)\end{array}$ & $\begin{array}{l}12 \%(90) \\
48 \%(364) \\
40 \%(309)\end{array}$ \\
\hline $\begin{array}{l}\text { Exposed to teachers smoking inside sc } \\
\text { Every day } \\
\text { Sometimes } \\
\text { Never } \\
\text { Frequency missing }=28\end{array}$ & $\begin{array}{l}42 \%(302) \\
44 \%(320) \\
14 \%(101)\end{array}$ & $\begin{array}{l}41 \%(314) \\
47 \%(358) \\
12 \%(92)\end{array}$ \\
\hline $\begin{array}{l}\text { Exposed to students smoking outdoors } \\
\text { Every day } \\
\text { Sometimes } \\
\text { Never } \\
\text { Frequency missing=29 }\end{array}$ & $\begin{array}{l}58 \%(419) \\
33 \%(243) \\
9 \%(63)\end{array}$ & $\begin{array}{l}63 \%(483) \\
29 \%(221) \\
8 \%(57)\end{array}$ \\
\hline Smoking prevalence in class $>20 \% *$ & $41 \%(307)$ & $46 \%(355)$ \\
\hline $\begin{array}{l}\text { Father smokes* } \\
\text { Frequency missing }=103\end{array}$ & $48 \%(324)$ & $52 \%(382)$ \\
\hline $\begin{array}{l}\text { Mother smokes }{ }^{*} \\
\text { Frequency missing }=80\end{array}$ & $40 \%(279)$ & $47 \%(351)$ \\
\hline $\begin{array}{l}\text { Best friend smokes* } \\
\text { Frequency missing }=75\end{array}$ & $44 \%(303)$ & $54 \%(400)$ \\
\hline
\end{tabular}

\section{RESULTS}

Table 1 indicates that $16 \%$ of boys and $22 \%$ of girls reported smoking on a daily basis, with 13\% of boys and 19\% of girls reporting to be heavy smokers. Three fifths of both sexes reported that they were exposed to teachers smoking outdoors on the school premises, with a significant minority reporting to see teachers smoking every day. In addition, the vast majority of students reported being exposed to teachers smoking inside the school building every day or sometimes. Of those students reporting exposure to teachers smoking inside the school building, most reported that they were exposed to teachers smoking in the staffroom (57\%), with fewer reporting seeing teachers smoking in the corridors $(16 \%)$ or in other parts of the school building (27\%). Approximately $90 \%$ of boys and girls reported being exposed to other students smoking on the school premises. Approaching half of the students reported parents or best friends who were smokers.

Table 2 shows that in the bivariate analyses, adolescents' perceived exposure to teachers smoking outdoors was significantly related to daily smoking (OR $2.1,98 \%$ CI 1.4 to 3.0 ). The strength of the association was reduced following adjustment for other smoking exposures and sex, but remained significant (adjusted OR 1.8, 98\% CI 1.2 to 2.8). In neither the bivariate nor multivariate model was perceived exposure to teachers smoking inside the school building significantly associated with daily smoking (adjusted OR $0.9,98 \%$ CI 0.5 to 1.6). Perceived exposure to pupils smoking outdoors was associated with daily smoking in the bivariate analyses (OR 3.7, 98\% CI
1.4 to 9.9 ), but the association was reduced and not significant in the multivariate analyses (adjusted OR 1.5, 98\% CI 0.5 to 4.4). As expected from earlier research, smoking among best friends was associated with daily smoking (adjusted OR 9.1, $98 \%$ CI 5.5 to 15.1 ), with a reduced but significant association between mothers' smoking and students' smoking behaviour (adjusted OR 1.7, 98\% CI 1.1 to 2.6) and between fathers' smoking and students' smoking behaviour (adjusted OR 1.9, 98\% CI 1.3 to 3.0). For heavy smoking, similar findings emerged, such that there was an association with exposure to teachers smoking outdoors on the school premises (adjusted OR $2.0,98 \%$ CI 1.2 to 3.1 ), but not with exposure to teachers smoking inside the school building (adjusted OR 0.9, 98\% CI 0.5 to 1.7) or exposure to students smoking outdoors (adjusted OR 1.6, 98\% CI 0.5 to 5.0).

All the analyses reported above were repeated for weekly smoking versus non-weekly smoking and for smokers versus non-smokers; however, the associations were stronger for daily and heavy smoking, hence these outcomes being presented here. Furthermore, all analyses were initially undertaken separately for boys and girls, but in the absence of a significant sex effect, the results have been presented for both sexes together.

\section{DISCUSSION}

The present study, based on a random sample of Danish schools, showed that adolescents' exposure to teachers and other pupils smoking during the school day is common. Three 
Table 2 Percentage (and number), crude and adjusted odds ratio (OR), and 98\% confidence intervals (Cl) of students daily smoking and heavy smoking in relation to perceived exposure to teachers smoking outdoors on school grounds and inside school building, sex, perceived exposure to students smoking outdoors on school premises, proportion of smokers in the class, parental smoking, and best friends smoking behaviour

\begin{tabular}{|c|c|c|c|c|c|c|}
\hline Variable & $\begin{array}{l}\text { Daily smokers } \\
(\% \text { (No.)) }\end{array}$ & $\begin{array}{l}\text { Crude ORt } \\
(98 \% \mathrm{Cl})\end{array}$ & $\begin{array}{l}\text { Adjusted OR† } \\
(98 \% \mathrm{CI})\end{array}$ & $\begin{array}{l}\text { Heavy smokers } \\
(\%(\text { No.)) }\end{array}$ & $\begin{array}{l}\text { Crude OR } \neq \\
(98 \% \mathrm{Cl})\end{array}$ & $\begin{array}{l}\text { Adjusted OR } \\
(98 \% \mathrm{Cl})\end{array}$ \\
\hline \multicolumn{7}{|c|}{$\begin{array}{l}\text { Exposed to teachers smoking } \\
\text { outdoors }\end{array}$} \\
\hline No & $12 \%(61)$ & $1^{*}$ & $1^{*}$ & $10 \%(50)$ & $1^{*}$ & $1 *$ \\
\hline Yes & $22 \%(173)$ & $2.1(1.4$ to 3.0$)$ & $1.8(1.2$ to 2.8$)$ & $19 \%(155)$ & $2.3(1.5$ to 3.4$)$ & $2.0(1.2$ to 3.1$)$ \\
\hline \multicolumn{7}{|c|}{$\begin{array}{l}\text { Exposed to teachers smoking } \\
\text { inside school building }\end{array}$} \\
\hline No & $17 \%(29)$ & $1^{*}$ & $1^{*}$ & $14 \%(24)$ & $1 *$ & $1^{*}$ \\
\hline Yes & $18 \%(205)$ & $1.1(0.6$ to 1.8$)$ & $0.9(0.5$ to 1.6$)$ & $16 \%(181)$ & 1.1 (0.7 to 2.0$)$ & $0.9(0.5$ to 1.7$)$ \\
\hline \multicolumn{7}{|l|}{ Sex } \\
\hline Boy & $14 \%(89)$ & $1^{*}$ & $1^{*}$ & $12 \%(78)$ & 1 * & $1^{*}$ \\
\hline Girl & $21 \%(145)$ & $1.6(1.1$ to 2.3$)$ & $1.3(0.9$ to 1.9$)$ & $18 \%(127)$ & $1.6(1.1$ to 2.3$)$ & $1.3(0.9$ to 2.0$)$ \\
\hline \multicolumn{7}{|c|}{$\begin{array}{l}\text { Exposed to pupils smoking } \\
\text { outdoors }\end{array}$} \\
\hline No & $6 \%(6)$ & $1^{*}$ & $1^{*}$ & $5 \%(5)$ & $1 *$ & $1^{*}$ \\
\hline Yes & $19 \%(228)$ & 3.7 (1.4 to 9.9 ) & $1.5(0.5$ to 4.4$)$ & $16 \%(200)$ & 3.9 (1.3 to 11.5$)$ & $1.6(0.5$ to 5.0$)$ \\
\hline \multicolumn{7}{|c|}{ Proportion of smokers in the class } \\
\hline$<20 \%$ smokers & $9 \%(66)$ & $1^{*}$ & $1^{*}$ & $8 \%(58)$ & 1 * & 1 * \\
\hline$>20 \%$ smokers & $30 \%(168)$ & $4.4(3.1$ to 6.4$)$ & $3.7(2.5$ to 5.5$)$ & $26 \%(147)$ & $4.2(2.9$ to 6.3$)$ & $3.3(2.2$ to 5.1$)$ \\
\hline \multicolumn{7}{|c|}{$\begin{array}{l}\text { Parents' smoking behaviour } \\
\text { Father }\end{array}$} \\
\hline Non-smoker & $11 \%(77)$ & $1^{*}$ & $1 *$ & $11 \%(77)$ & $1^{*}$ & $1^{*}$ \\
\hline Smoker & $25 \%(157)$ & 2.6 (1.8 to 3.8$)$ & $1.9(1.3$ to 3.0$)$ & $20 \%(128)$ & $2.0(1.4$ to 2.9$)$ & $1.4(0.9$ to 2.2$)$ \\
\hline \multicolumn{7}{|l|}{ Mother } \\
\hline Non-smoker & $12 \%(96)$ & $1^{*}$ & $1^{*}$ & $11 \%(89)$ & $1^{*}$ & $1^{*}$ \\
\hline Smoker & $26 \%(138)$ & 2.6 (1.8 to 3.6$)$ & $1.7(1.1$ to 2.6$)$ & $22 \%(116)$ & $2.2(1.6$ to 3.2$)$ & $1.6(1.0$ to 2.4$)$ \\
\hline \multicolumn{7}{|c|}{ Best friends' smoking behaviour } \\
\hline Non-smoker & $4 \%(29)$ & $1^{*}$ & $1^{*}$ & $3 \%(24)$ & $1^{*}$ & $1 *$ \\
\hline Smoker & $34 \%(205)$ & 11.9 (7.3 to 19.3$)$ & 9.1 (5.5 to 15.1$)$ & $30 \%(181)$ & $12.2(7.2$ to 20.6$)$ & $9.2(5.4$ to 15.7$)$ \\
\hline
\end{tabular}

fifths of the students in the study reported that they had seen or knew of teachers smoking outdoors on the school premises, and most of them reported that they had seen or knew of teachers smoking inside the school building. The vast majority of students reported seeing or knowing of other students smoking outdoors on the school premises. This suggests that there is a degree of tolerance towards smoking in Danish schools, which may influence student beliefs and attitudes towards smoking. As noted earlier, according to the theory of planned behaviour ${ }^{8}$ a high tolerance towards smoking at school is likely to influence students, making them more likely to perceive smoking as something positive and acceptable, developing favourable personal beliefs and subjective norms about smoking, leading to intentions to take up the habit.

An important finding to emerge from this study is the positive association between teachers smoking in the school setting and adolescents smoking behaviour. Students' exposure to teachers smoking outdoors on school premises was significantly associated with smoking behaviour, having adjusted for exposure to close social relations' smoking habits and sex. On the other hand, exposure to teachers smoking inside the school building was not significantly associated with adolescent smoking behaviour. This suggests that teachers smoking a cigarette outdoors in the playground in front of students might be of greater importance than exposure to teachers smoking in the staffroom, which is more likely to be less frequent and shorter in duration. This finding implies that the aims of school smoking policies restricting teachers smoking should include tackling the issue of students' exposure to adult smoking outdoors. In Norway, where comprehensive policies restricting smoking in schools are in place, smoking by teachers in the school buildings is prohibited. However, the aim of the existing policy regarding smoking among teachers focuses on protecting individuals from the harmful effects of exposure to tobacco smoke rather than reducing adolescent exposure to adult smokers. The prohibition of indoor smoking by teachers has led to an increase in smoking outdoors on the school premises, thus increasing the potential for students to be exposed to smokers when at school.

To date, a limited number of studies have focused on the relation between teachers' smoking and adolescent smoking behaviour. For example, a study of approximately $600011-12$ year olds and 1300 teachers in England suggested that variations between schools in the prevalence of smoking by teachers were linked to variations in the prevalence of student smoking, with a higher proportion of student smokers found in schools with a higher proportion of smokers among the teaching staff. ${ }^{24}$ However, in another study in England with 2159 11-13 year olds, no association was found between smoking among teachers and student smoking, although "believing that teachers would not mind if they smoked" predicted future smoking uptake among the young people. ${ }^{25}$

There was no significant association between exposure to other pupils smoking outdoors and adolescent smoking behaviour; an explanation for this is that very few pupils (only $9 \%$ ) reported that they never saw other pupils smoke. It has been suggested that the association between smoking prevalence and other pupils smoking is overestimated because 
smokers tend to spend time with other smokers (selection) and smokers are more likely to be aware of others who smoke (projection). ${ }^{26}$ The projection hypothesis is supported by the reported high proportion of smoking best friends, and the age of the participating adolescents, as the smoking behaviour of 15-16 year old adolescents probably is largely established.

The findings presented here also confirm those of numerous studies elsewhere, indicating a strong association between adolescent smoking behaviour and the smoking status of best friends, and a more moderate association with parental smoking. ${ }^{61011}$ This supports the notion that exposure to smoking by potential important role models can influence adolescent smoking ${ }^{6}{ }^{10}$ and that teachers who smoke in front of students in school function as role models.

It is important to assess the key strengths and potential limitations of the study design. The major strength of the study is that it is based on a large sample of students from randomly selected schools in Denmark, with a high participation rate achieved. The study population is therefore likely to be representative. In order to assess potential selection bias, bivariate analyses were performed on those data with a valid response for each variable of interest and those with data for all variables of interest. These analyses produced similar results. Furthermore, subjects with incomplete data were comparable to those with complete data in terms of sex and smoking behaviour. Thus, we have no reason to believe that the results from the multivariate analyses would differ if all students had provided valid information on all variables.

Given the cluster sampling approach used to select pupils, we have employed an estimated design effect from an earlier study to account for intraclass correlation. Furthermore, a variable indicating the proportion smoking in each class was included in the analysis to further adjust for intraclass correlation. The study does have potential limitations. Firstly, the study relies on self reported measures for student exposure to others smoking. There is evidence that people tend to project their own behaviour onto others-for example, smokers are more likely to be aware of others who smoke. ${ }^{26}$ Such a misclassification of teachers' smoking might have influenced the positive association found in this study. Secondly, self reported measures of smoking status are used. Studies suggest that students who smoke appear to deny this, even when biochemical measures classify them as smokers. ${ }^{27}$ However, in this study two different measures were used, daily and heavy smoking, with the results being very similar. Thirdly, given the cross sectional study design, evidence of an association should be interpreted with some caution before a causal relation is claimed. For example, students who smoke may spend more time outdoors than non-smoking students, or students who smoke might be more aware of teachers who smoke, which may account for some of the association between adolescent smoking and exposure to teachers smoking outdoors. We recommend that studies with a longitudinal design should explore the effect of smoking policy.

\section{Conclusions}

Our study emphasises the importance of a smokefree school environment by suggesting that exposure to teachers smoking during school hours influence the smoking behaviour of adolescents. This finding has implications for future tobacco prevention strategies in schools in many countries with liberal smoking policies where it might provide support for those working to establish smokefree schools. The result could also be used as an argument for reducing students exposure to teachers smoking in other settings.

\section{ACKNOWLEDGEMENTS}

We thank CAS (Control of Adolescent Smoking) study colleagues involved in developing this study: Bente Wold (Norway), Candace Currie and Dawn Griesbach (UK), Bettina Schmidt (Germany), Danielle Piette (Belgium), Wolfgang Dür (Austria), Lasse Kannas and

\section{What this paper adds}

Recent studies suggest that the prevalence of smoking among adolescents is lower in school settings with strongly enforced smoking restrictions. There is conflicting evidence regarding the association between teachers' smoking and adolescent smoking behaviour. Our study suggests that exposure to teachers smoking outside on the school premises is an important predictor of adolescent smoking behaviour. This finding has implications for future tobacco prevention strategies in schools in those countries with liberal smoking policies, providing support for those working to establish smokefree schools.

Jorma Tynjälä (Finland). Supported by the Danish Cancer Society, Psychosocial Research Foundation No. 98150 08, and the Health Insurance Foundation No. 11/216-98. The study has also received support from the European Commission, through Concerted Action Contract BMH4-CT98-3721 (DG 12-SSMI). CR is also funded by the National Assembly for Wales. The views expressed in this paper are those of the authors and not necessarily those of the National Assembly for Wales.

\section{Authors' affiliations}

L H Poulsen, M Osler, C Roberts, P Due, M T Damsgaard, B E

Holstein, Department of Social Medicine, University of Copenhagen, Institute of Public Health, Copenhagen, Denmark

\section{REFERENCES}

1 Peto R, Lopez AD, Boreham J, et al. Mortality from smoking in developed countries 1950-2000. Indirect estimates from national vital statistics. Oxford: Oxford University Press, 1994.

2 Elders MJ, Cheryl PL, Eriksen MP, et al. The Report of the Surgeon General: Preventing tobacco use among young people. American Journal of Public Health 1994:84:543-547.

3 King A, Wold B, Tudor-Smith C, et al. The health of youth: a cross-national survey. World Health Organization Regional Publications, European series No. 69, 1996.

4 Curry C, Hurrelman K, Settertobulte W, et al. Health and health behaviour among young people. World Health Organization Policy Series: Health policy for children and adolescents (HEPCA) series No. 1 2000.

5 Due P, Holstein BE. Rygevaner blandt 1 1-15 årige, 1984-94 (in Danish) Ugeskrift for Laeger 1997;159:1090-109.

6 Conrad KM, Flay BR, Hill D. Why children start smoking cigarettes: predictors of onset. Br J Addiction 1992;87:171 1-24.

7 Chassin L, Presson CC, Sherman SJ. Social psychological contributions to the understanding and preventions of adolescent cigarette smoking. Personality and Social Psychological Bulletin 1990;16:133-51.

8 Aizen I. Attitudes, personality and behaviour. Milton Keynes: Open University Press, 1988

9 Bandura A. Social foundations of thought and action, a social cognitive theory. Englewood Cliffs, New Jersey: Prentice Hall, 1986.

10 Tyas SL, Pederson LL. Psychosocial factors related to adolescent smoking: a critical review of the literature. Tobacco Control 1998;7:409-20.

11 Bauman KE, Ennett ST. On the importance of peer influence for adolescent drug use: commonly neglected considerations. Addiction 1996;91:185-98.

12 Reid DJ, McNeill AD, Glynn TJ. Reducing the prevalence of smoking in youth in western countries: an international review. Tobacco Control 1995;4:266-77.

13 Nutbeam D, Smith C, Moore L, et al. Warning! Schools can damage your health: alienation from school and its impact on health behaviour. J Paediatr Child Health 1993;29(suppl 1):25-30.

14 Samdal O, Wold B, Klepp KI, et al. Students' perception of school and their smoking and alcohol use: a cross-national study. Addiction Research 2000;8: 141-67.

15 Pentz MA, Brannon BR, Ventura L, et al. The power of policy: the relationship of smoking policy to adolescent smoking. Am J Public Health 1989:79:857-62.

16 Carolyn SC. Smoking areas on school grounds: are we encouraging teenagers to smoke? Journal of Adolescent Health Care 1984;5:117-19.

17 Wakefield MA, Chaloupka FJ, Kaufman NJ, et al. Effect of restrictions on smoking at home, at school, and in public places on teenage smoking: cross sectional study. BMV 2000;321:333-7.

18 Hartland J, Tudor-Smith C, Bowker S. Smoke-free policies in schools: a qualitative investigation of the benefits and barriers. Health Educ $J$ 1998;57:51-9

19 Dalla-Vorgia P, Sasco AV, Skalkidis Y, et al. An evaluation of the effectiveness of tobacco- control Legislative policies in European community Countries. Scand J Soc Med 1990;18:81-9. 
20 Harkin AM, Anderson P, Goos C. Smoking, drinking and drug taking in the European region. Copenhagen: World Health Organization, 1997.

21 Wold B, Holstein B, Griesbach D, et al. Control of adolescent smoking. National policies on restriction of smoking at school in eight European countries. University of Bergen: Research Centre for Health Promotion, 2000

22 Roberts C. Control of adolescent smoking. Technical report on staff survey in eight European countries. University of Edinburgh: Child and Adolescent Health Research Unit (CAHRU), 2000.

23 Davies HTO, Crombie IK, Tavakoli M. When can odds ratios mislead? BM 1998;316:989-91.
24 Bewley BR, Johnson MRD, Banks MH. Teachers' smoking. J Epidemiol Community Health 1979;33:219-22.

$25 \mathrm{McNeill}$ AD, Jarvis M, Stapleton JA, et al. Prospective study of factors predicting uptake of smoking in adolescents. J Epidemiol Community Health 1988;43:72-8

26 Marks G, Miller N. Ten years of research on the false-consensus effect: an empirical and theoretical review. Psychol Bull 1987:102:72-90.

27 Patrick DL, Cheadle A, Thompson DC, et al. The validity of self reported smoking: a review and meta-analysis. Am J Public Health 1994;84:1086-93.

The lighter side

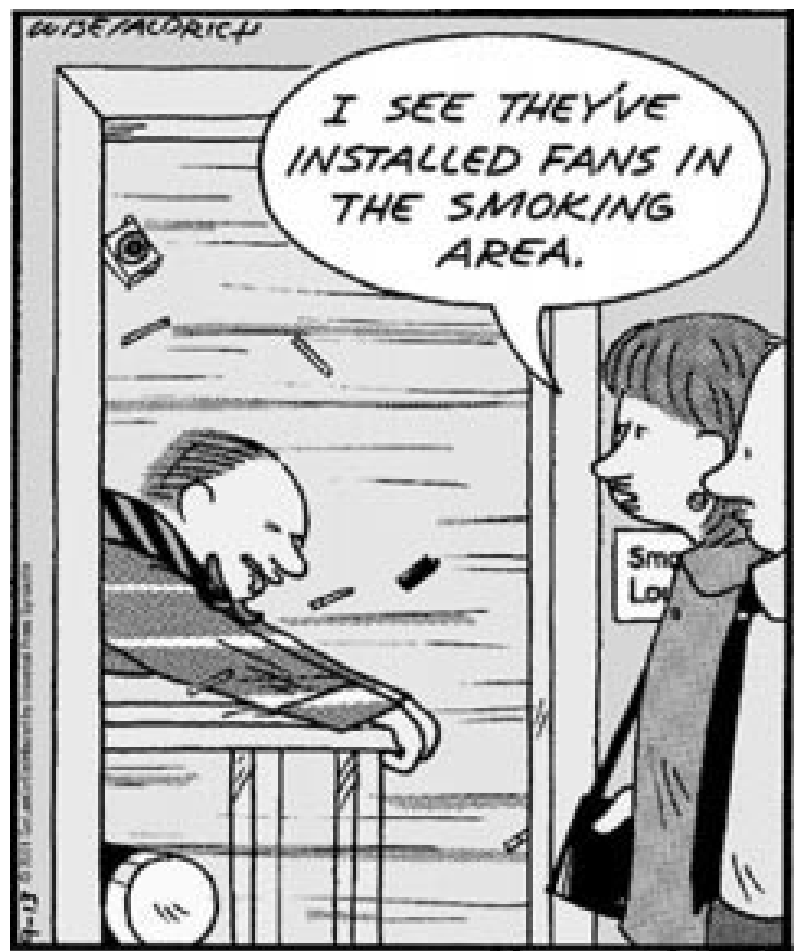

Real life adventures (C) 2001 by Garlanco. Reprinted with permission of Universal Press Syndicate. All rights reserved.

\section{Just a little subliminal message from me to my employees who sinoke.}

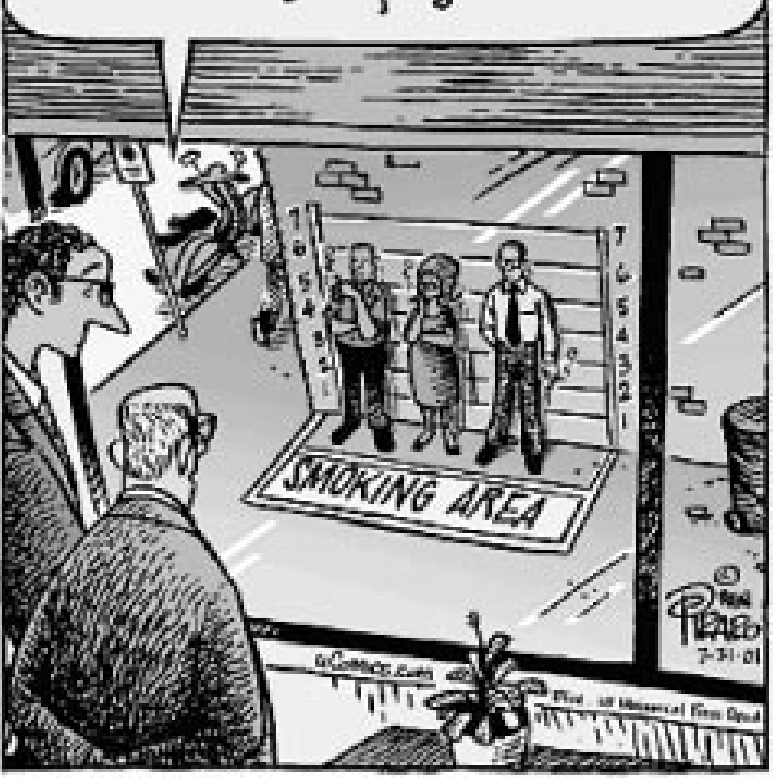

Bizarro (c) 2001 by Dan Piraro. Reprinted with permission of Universal Press Syndicate. All rights reserved. 